\title{
Rising air and stream-water temperatures in Chesapeake Bay region, USA
}

\author{
Karen C. Rice • John D. Jastram
}

Received: 7 November 2013 / Accepted: 12 November 2014 / Published online: 26 November 2014

(C) Springer Science+Business Media Dordrecht (outside the USA) 2014

\begin{abstract}
Monthly mean air temperature (AT) at 85 sites and instantaneous stream-water temperature (WT) at 129 sites for 1960-2010 are examined for the mid-Atlantic region, USA. Temperature anomalies for two periods, 1961-1985 and 1985-2010, relative to the climate normal period of 1971-2000, indicate that the latter period was statistically significantly warmer than the former for both mean AT and WT. Statistically significant temporal trends across the region of $0.023{ }^{\circ} \mathrm{C}$ per year for AT and $0.028^{\circ} \mathrm{C}$ per year for WT are detected using simple linear regression. Sensitivity analyses show that the irregularly sampled WT data are appropriate for trend analyses, resulting in conservative estimates of trend magnitude. Relations between 190 landscape factors and significant trends in AT-WT relations are examined using principal components analysis. Measures of major dams and deciduous forest are correlated with WT increasing slower than AT, whereas agriculture in the absence of major dams is correlated with WT increasing faster than AT. Increasing WT trends are detected despite increasing trends in streamflow in the northern part of the study area. Continued warming of contributing streams to Chesapeake Bay likely will result in shifts in distributions of aquatic biota and contribute to worsened eutrophic conditions in the bay and its estuaries.
\end{abstract}

\section{Introduction}

The Fifth Assessment Synthesis Report of the Intergovernmental Panel on Climate Change (IPCC) states that although sea ice has been melting, global ocean heat content has increased; in addition, both land and ocean surface temperatures have increased (IPCC 2013). Over the period 1951-2012, global mean surface temperature increased approximately $0.12{ }^{\circ} \mathrm{C}$ per decade (IPCC 2013). Increasing trends in stream-water temperature (WT) have been observed

Electronic supplementary material The online version of this article (doi:10.1007/s10584-014-1295-9) contains supplementary material, which is available to authorized users.

K. C. Rice $(\square)$

U.S. Geological Survey and Department of Environmental Sciences, University of Virginia, P.O. Box 400123, Charlottesville, VA 22904, USA

e-mail: kcrice@usgs.gov

J. D. Jastram

U.S. Geological Survey, 1730 East Parham Road, Richmond, VA 23228, USA 
at regional (e.g., Mohseni et al. 1999; Webb and Nobilis 2007; Kaushal et al. 2010; Isaak et al. 2012) as well as global scales (van Vliet et al. 2011). The literature reflects disagreement regarding the control of air temperature (AT) on WT. Some studies conclude that AT does not control WT (e.g., Johnson 2003; Arismendi et al. 2012; Mayer 2012), whereas modeling studies show that AT is a strong predictor of WT (e.g., Webb et al. 2003; Moatar and Gailhard 2006; van Vliet et al. 2011; Isaak et al. 2012). Statistical studies, such as this one, can be complimentary to processoriented studies in identifying factors that may be driving increasing WT trends. Whether or not rising WT is driven by rising AT, the end result is that stream ecosystems and aquatic biota will be affected once WT reaches a critical threshold (Caissie 2006; van Vliet et al. 2013). In addition, rising WT of source waters can affect industry, electricity, and drinking water, as well as recreation (van Vliet et al. 2011).

The biological, physical, and biogeochemical consequences of increasing WT are myriad, intertwined, and largely nonlinear. From a biological standpoint, rising WT of both freshwater and estuarine systems alters species ranges and community composition of phytoplankton (Coles and Jones 2000), submerged aquatic vegetation (Short and Neckles 1999; Najjar et al. 2010), and fish (Beitinger et al. 2000; Isaak et al. 2012). From a physical standpoint, warming of waters decreases dissolved oxygen and can cause changes in density, circulation patterns, and stratification (Scavia et al. 2002; Harley et al. 2006; Najjar et al. 2010). From a biogeochemical standpoint, eutrophication - a world-wide problem of polluted estuaries (Bricker et al. 2007) - is expected to worsen as WT rise (Scavia et al. 2002; Rabalais et al. 2009; Najjar et al. 2010).

Chesapeake Bay is the largest estuary in the USA. The $166,319-\mathrm{km}^{2}$ watershed (CBW), the focus of this study, includes parts of New York, Pennsylvania, Delaware, Maryland, Virginia, and West Virginia (Fig. 1). Land cover within the CBW comprises $65.2 \%$ forest and wetland; $22.2 \%$ agriculture; $12.0 \%$ urban; and $0.6 \%$ other (Peter Claggett, USGS, written comm. 2012). The estuary has a surface area of $11,655 \mathrm{~km}^{2}$, yielding a land-to-water ratio of over 14:1. Such a high ratio helps to explain the significant influence that the watershed has on the water quality of the bay (e.g., Hagy et al. 2004). Chesapeake Bay is a focus for major ecosystem rehabilitation efforts because it has been plagued by eutrophication for decades (Hagy et al. 2004; Bricker et al. 2014). Increasing WT of streams significantly increases nutrient concentrations, which contribute to eutrophication (Duan and Kaushal 2013). Preston (2004) indicates that Chesapeake Bay waters are warming, furthering eutrophic conditions.

Previous work on WT trends in the mid-Atlantic region of the eastern USA indicates warming streams. Kaushal et al. (2010) report that most streams examined in the midAtlantic region have statistically significant increasing WT trends. Seekell and Pace (2011) analyzed 100-year AT and WT records for the Hudson River Estuary, New York, and found statistically significant increasing trends in both. Limitations of the previous work in the mid-Atlantic region are that datasets of inconsistent length were used (Kaushal et al. 2010), which confounds comparison of results across sites (Schertz et al. 1991), or the work included only one site (Seekell and Pace 2011). The impending deleterious effects of rising WT on Chesapeake Bay water quality suggest that a more focused analysis of WT trends across the CBW and the physical characteristics that could mitigate or exacerbate those trends is needed.

In this paper, we expanded the previous work in the mid-Atlantic region by drawing on a much larger dataset of consistent length. Our AT and WT data extend more than 50 years and cover most of the $\mathrm{CBW}$ and beyond. The importance of long-term data such 

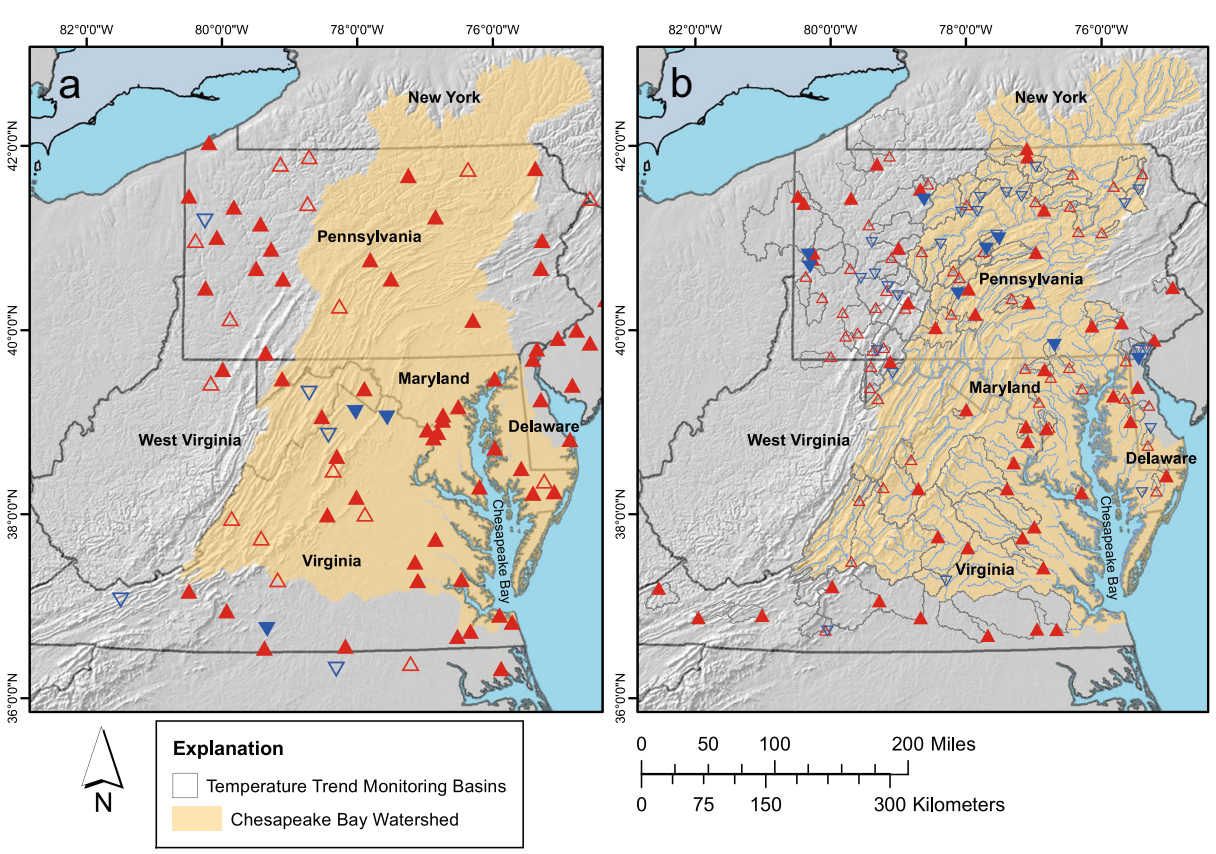

Fig. 1 Maps showing Chesapeake Bay watershed, locations of sites, and temporal trends for 1960-2010 for a) monthly mean air temperature, and b) instantaneous stream-water temperature. Red symbols indicate increasing trends and blue symbols indicate decreasing trends. Solid and open symbols show trends that are statistically significant and not significant, respectively

as these for detecting linear trends is emphasized by the definition of the quantitative power of a trend test, as follows:

$$
\text { Power }=f\left(b / s * n^{1.5}\right),
$$

where $\mathrm{b}$ is the trend slope, $\mathrm{s}$ is the standard deviation of the error, and $\mathrm{n}$ is the number of observations. By analyzing 51-year AT and WT datasets, we evaluated the following: (1) changes in the distribution of AT and WT anomalies for 1961-1985 and 1986-2010 compared to a climate normal period of 1971-2000; (2) temporal trends in AT and WT across the region for 1960-2010; (3) relations between landscape factors and WT trends; and (4) the influence of trends in streamflow on WT trends.

\section{Methodology}

\subsection{Data compilation}

Long-term AT data for the region are readily available, but long-term WT data are less abundant. WT sites were selected to achieve a balance between the largest number of sites (129) and the longest period of record in common (51 years). Sufficient WT data for streams in New York and West Virginia were not available in an electronic database, eliminating coverage of about $15 \%$ of the CBW (Fig. 1). 
Monthly mean AT data for 1960-2010 were downloaded from the National Climatic Data Center (www.ncdc.noaa.gov). We selected 85 sites with data completeness ranging from 87 to $100 \%$ (median $99 \%$ ) to obtain sufficient spatial distribution across the region (Fig. 1a). Land-surface elevations of the AT sites range from 2.6 to $1,078 \mathrm{~m}$ above sea level (ESM Table 1). Of the 85 sites, 39 are part of the U.S. Historical Climatology Network, a highquality dataset used to assist in the detection of regional climate change. For 1960-2010, the number of observations per AT site ranged from 535 to 612 with a mean of 600 .

Instantaneous WT data were obtained from the U.S. Geological Survey (USGS) National Water Information System database. Sites with streamgages were chosen on the basis of completeness of WT data for 1960-2010, using a criterion of having data in at least $90 \%$ of the 51 years. The WT dataset consists of 129 sites (Fig. 1b), of which 104 are independent, i.e., 104 of the watersheds do not have another site nested within it. WT was measured by USGS staff while making streamflow measurements near the streamgage by placing a calibrated thermometer directly in the stream. At the 129 sites, these measurements were made on average eight times per year, with the number of measurements at a site ranging from 0 to 27 per year. Variability in measurement frequency is unique among sites and across years; it does not have any apparent structure, such as a concentration of measurements during only part of the record or measurements limited to a specific season, either of which could bias trend calculations (ESM Fig. 1). The 129 streamgages have land-surface elevations ranging from 2.0 to $719 \mathrm{~m}$ above sea level and watershed areas ranging from 8.4 to $16,207 \mathrm{~km}^{2}$ (ESM Table 2). Such large ranges in elevations and watershed areas suggest that flow and channel geometry of these lotic systems vary widely; for simplicity, we refer to all of these systems as "streams."

The WT dataset was screened for measurement and data-entry errors by removing values outside the -5 to $40^{\circ} \mathrm{C}$ range. For each site, the monthly standard deviation was computed and values greater than three times the standard deviation were removed. The screening eliminated 344 values from the initial dataset of 49,304 values. For 1960-2010, the number of observations per WT site ranged from 262 to 605 with a mean of 380 .

Physical characteristics of the landscape that could influence WT trends for each watershed were extracted from the Geospatial Attributes of Gages for Evaluating Streamflow Version II dataset (GAGESII; http://water.usgs.gov/GIS/metadata/usgswrd/XML/gagesII_Sept2011.xml, accessed 18 June 2013), an update to Falcone et al. (2010). Landscape factors extracted included 190 measures of location, topography, hydrology, soils, land cover, dams, and population density. The landscape factors consist of areal measures that characterize the entire watershed or areas within set distances of the stream channels (e.g., land cover), linear measures that represent the stream channel (e.g., stream order), and point measures that represent location of the streamgage (e.g., latitude and longitude).

\subsection{Statistical}

To achieve our primary goal of determining if there have been changes in measured AT and WT for the period 1960-2010, we analyzed the extensive datasets by two methods. First, we evaluated changes in the mean AT and WT anomalies for the first half of the period relative to the second half by calculating AT and WT anomalies for 1961-2010 relative to the climate normal period of 1971-2000. For both AT and WT, anomalies were calculated as the difference between the observed values (monthly mean AT and instantaneous WT) and the site-specific monthly mean for 1971-2000. Although climate normal periods are 30 years (e.g., Donat and Alexander 2012), our 51-year dataset required the use of two 25-year periods for comparison of the anomalies. We constructed probability density functions (pdfs) for 1961-1985 (former period) and 1986-2010 (latter period) relative to 1971-2000 for both 
AT and WT following methods of Donat and Alexander (2012). We tested for differences in the means of the anomalies of the former and latter periods using a Student's $t$-test and a Rank Sum test.

Second, we determined temporal trends in AT and WT measurements. Because of the likelihood of seasonality in the residuals of linear regression, and to address potential bias resulting from the irregular-interval WT data, we fit a simple linear regression (SLR) to the AT and WT anomalies at each site for $1960-2010$ by use of:

$$
y=\beta_{0}+\beta_{1}(t)
$$

where $\mathrm{y}$ is the observed monthly mean AT anomaly or instantaneous WT anomaly in ${ }^{\circ} \mathrm{C}$; $\mathrm{t}$ is decimal time (year+julian date/days per year); $\beta_{0}$ is the intercept; and $\beta_{1}$ describes the trend $\left({ }^{\circ} \mathrm{C}\right.$ per year). Anomalies were calculated as observed monthly mean AT or instantaneous WT subtracted from the site-specific monthly mean AT or WT of the entire period (1960-2010). Serial correlation of residuals was tested using Spearmans Rho on the lagged residuals (Helsel and Hirsch 1992). If significant serial correlation of the residuals was absent $(p \geq 0.05)$, trends of the anomalies were calculated by use of Eq. 2. If serial correlation was present $(p<0.05)$, trends were determined by use of the Cochrane-Orcutt method (Cochrane and Orcutt 1949) to remove the serial correlation. We evaluated the significance of regional trends on the collection of trend slopes $\left(\beta_{1}\right)$ for AT and WT using the Wilcoxon signedrank test (Helsel and Hirsch 1992).

We tested the suitability of the irregular-interval WT data to evaluate trends by two methods. First, we used bootstrapping (Efron 1979) on the SLRs using 1,000 bootstrapped resamples of the WT data for each of the 129 WT sites. Sensitivity of the trend results was evaluated using the bootstrapped $95 \%$ confidence interval of the trend slope, focusing on whether the confidence interval indicated non-significance of significant SLR trends, i.e., whether the confidence interval crossed zero. Second, we developed a synthetic 51-year dataset based on eight years of measured continuous (15-min interval) WT data from the James River at Cartersville, Virginia (USGS Station 02035000), from 2005 to 2012. We randomly selected a year of measured continuous data to represent each of 51 years, resulting in a 51-year synthetic WT dataset containing natural diurnal and seasonal variability with no long-term trend. To the synthetic dataset, we applied: (1) a decreasing trend of $0.023{ }^{\circ} \mathrm{C}$ per year; (2) no trend; and (3) an increasing trend of $0.023{ }^{\circ} \mathrm{C}$ per year. The rate of $0.023{ }^{\circ} \mathrm{C}$ per year was the calculated median AT trend and is within the range of observed WT trends. We sampled the synthetic dataset using the actual date/time of the WT data collected at each of 28 of our original WT sites and calculated the 28 trends for each of the three groups by use of the trend-analysis methods described above.

We examined relations between AT and WT by pairing each WT site that had a significant WT trend with the geographically closest AT site and assessed whether those relations changed over time. Temporal pairings of measurements were then made from the spatially paired sites by pairing the WT measurements with the monthly mean AT of the month in which the WT measurement was made (ESM Fig. 2a). We considered pairing instantaneous WT measurements with daily AT, however, better regression fits were found for monthly mean AT than for daily AT (ESM Fig. 2b). We attributed the better fits to the thermal inertia of streams caused by the spatial integration of climatic conditions and thermal processes across a watershed. Regression was used to determine the relation between monthly AT (explanatory variable) and instantaneous WT (dependent variable), using the Cochrane-Orcutt method to remove serial correlation. To evaluate whether the AT-WT relation changed over time, residuals from 
the regressions of the paired data were regressed against decimal time. A positive trend in the residuals indicated that WT increased faster than AT, and a negative trend indicated that WT increased slower than AT, presumably because of some effect of the landscape. A nonsignificant trend would indicate a static AT-WT relation.

A trend in the AT-WT relation would indicate that the effect of AT on WT changed over time, and such change may be associated with landscape factors. To evaluate which landscape factors may have affected WT trends at the sites with significant AT-WT relation trends, we applied principal components analysis (PCA) (Shaw 2003) to the 190 landscape factors from the GAGESII dataset to reduce the large number of factors to a manageable number of components. Correlations between components representing the greatest proportions of variability in the landscape factors and trends in AT-WT relations were then evaluated. Direct correlations between PCA components and AT-WT relation trends were interpreted as indicating an association between positively loaded landscape factors and the direction of the ATWT relation trend, whereas negatively loaded factors were associated with the inverse of the AT-WT trend direction.

To determine whether increasing stream discharge could have influenced the WT trends, we calculated stream discharge trends by use of Eq. 2 , with $\log _{10}$ of instantaneous streamflow at the time of WT measurement as the response variable (y), again using the Cochrane-Orcutt method to remove serial correlation. The resulting $\log _{10}$ streamflow annual trends were plotted against WT annual trends for graphical comparison.

\section{Results}

Differences in the AT anomalies for 1961-1985 and 1986-2010 were indicated by means of $-0.29^{\circ} \mathrm{C}$ for the former and $0.25^{\circ} \mathrm{C}$ for the latter period (Fig. 2a). For the WT anomalies, the means were -0.24 for the former and 0.14 for the latter period (Fig. 2b). Both a Student's $t$-test and a Rank Sum test indicated that the mean of the anomaly for the latter period for both AT and WT was significantly greater $(p<0.0001)$ (Fig. 2a and b) than that of the former period.

The SLR (Eq. 2) provided unbiased estimates of temporal trend in AT and WT, evidenced by homoscedastic residuals having a mean of zero. Because we used anomalies of measured temperatures, seasonality was not apparent in residual plots.

Evaluation of lagged residuals for AT temporal trend regressions indicated significant serial correlation at all 85 sites. Serial correlation was removed after one iteration of the CochraneOrcutt method. Of the 85 sites, 64 had significant trends $(p \leq 0.05)$, with 61 increasing and 3 decreasing (Fig. 1a). The median trend of the 64 sites with significant trends was $0.023{ }^{\circ} \mathrm{C}$ per year, which was regionally significant $(p<0.0001)$ according to the Wilcoxon Signed Rank test. The Wilcoxon Signed Rank test of all trend slopes (regardless of significance) indicated a significantly increasing regional trend $(p<0.0001)$ with a median of $0.020{ }^{\circ} \mathrm{C}$ per year.

Evaluation of lagged residuals for WT temporal trend regressions indicated significant serial correlation at 54 of the 129 sites. Serial correlation was removed after one iteration of the Cochrane-Orcutt method. Trends were computed directly on the anomalies for the 75 sites that did not have significant serial correlation by use of Eq. 2. Combined results of the two-step method yielded 57 sites with significant trends, 49 of which were increasing and eight decreasing (Fig. 1b). Of the 57 sites with significant trends, the median was $0.028{ }^{\circ} \mathrm{C}$ per year, which was regionally significant $(p<0.0001)$ according to the Wilcoxon Signed Rank test. The Wilcoxon Signed Rank test of all trend slopes (regardless of significance) indicated a significantly increasing regional trend $(p<0.0001)$ with a median of $0.012{ }^{\circ} \mathrm{C}$ per year. 

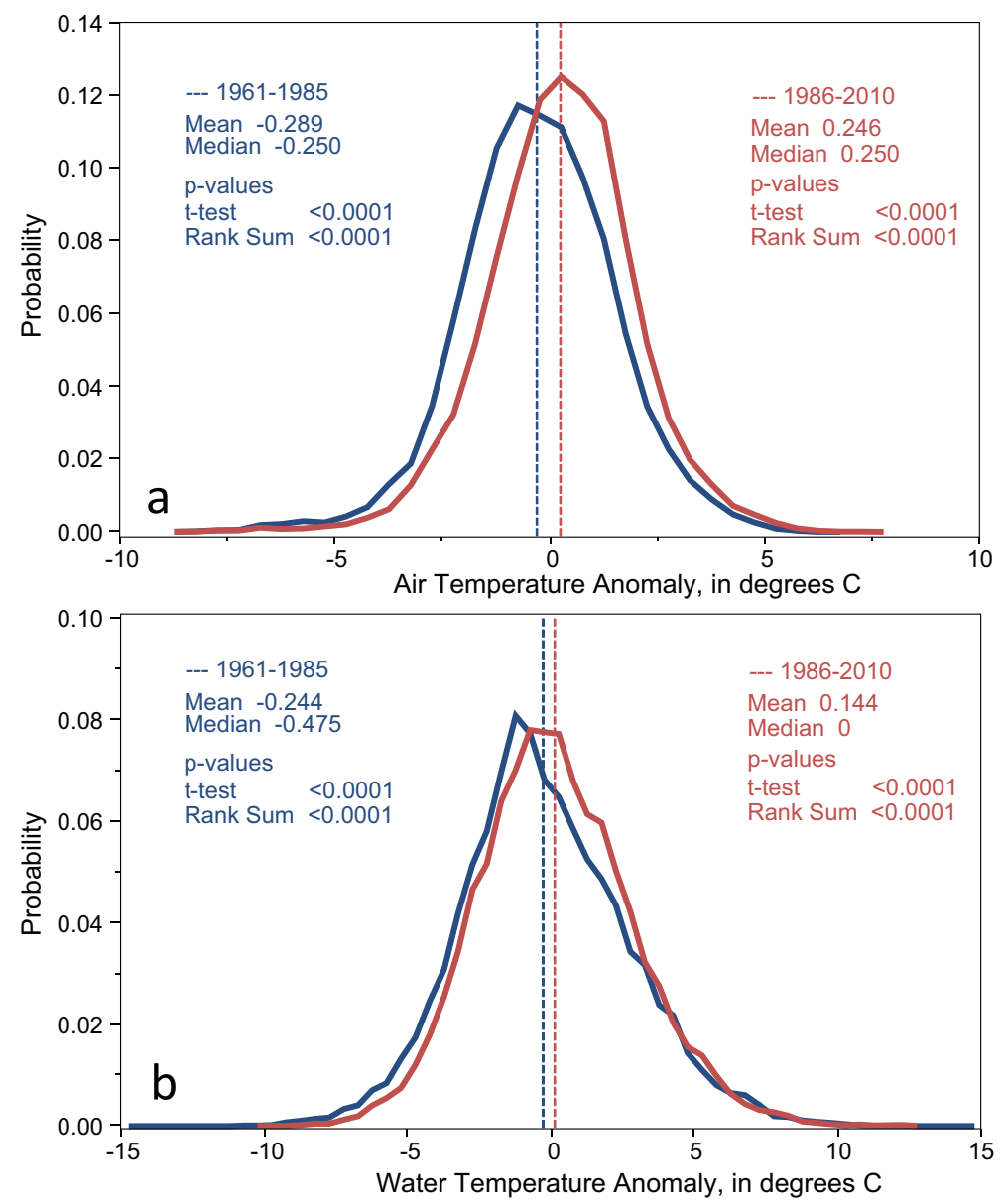

Fig. 2 Probability density functions (pdfs) of anomalies for 1961-1985 and 1986-2010 relative to 1971-2000 for $\mathbf{a}$ ) air temperature, and $\mathbf{b}$ ) stream-water temperature

Results of bootstrapping the trends of the WT anomalies indicated that the irregular-interval WT data did not affect the direction of the significant trends at any of the sites, as none of the bootstrapped confidence intervals included zero (Fig. 3). Results of 28 trends calculated on the 51-year synthetic dataset for each of the three groups were as follows: (1) decreasing trend of $0.023{ }^{\circ} \mathrm{C}$ per year: detected 19 significant decreasing trends, with a mean of $0.028^{\circ} \mathrm{C}$ per year; (2) no trend: detected one significant decreasing trend; and (3) increasing trend of $0.023{ }^{\circ} \mathrm{C}$ per year: 14 significant increasing trends, with a mean of $0.026{ }^{\circ} \mathrm{C}$ per year (ESM Fig. 2c).

One iteration of the Cochrane-Orcutt method removed serial correlation of the regressions of the paired AT and WT. The relation between AT and WT was significant for all 57 of the paired sites, with a median $\mathrm{R}^{2}$ value of 0.85 . Residuals from the regressions were then regressed over time: 46 sites had significant trends, 19 of which increased at a median rate of $0.032{ }^{\circ} \mathrm{C}$ per year (i.e., WT increased faster than AT), and 27 of which decreased at a median rate of $-0.034{ }^{\circ} \mathrm{C}$ per year (i.e., WT increased slower than AT).

Principal components analysis of the landscape factors yielded five components that cumulatively described $59 \%$ of the variability in landscape factors across the 57 sites with 


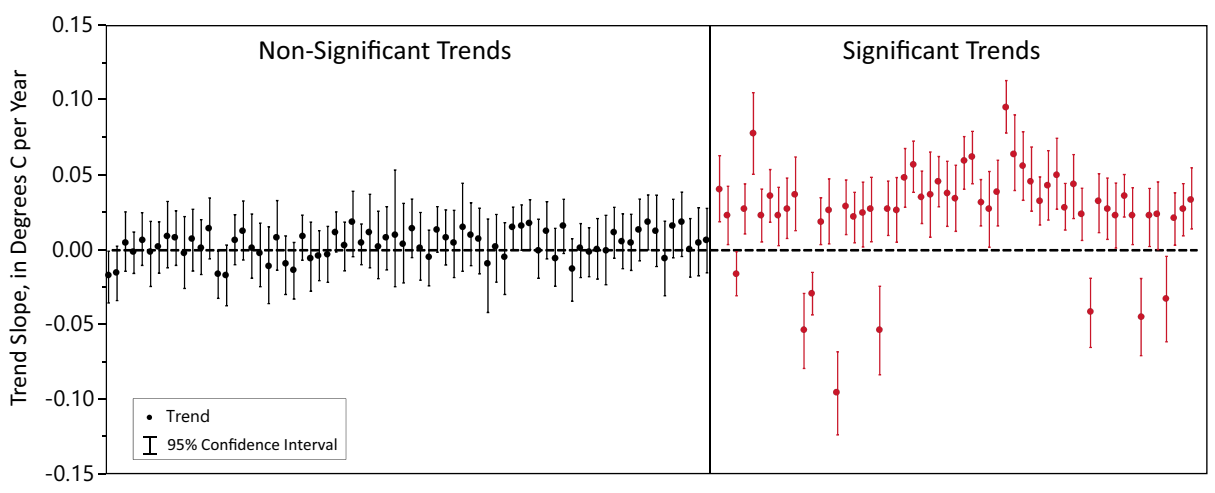

Fig. 3 Results of bootstrapping WT trends. Error bars show the $95 \%$ confidence interval for the bootstrapped results

significant trends in the AT-WT relation. Of the five components, three (2, 3, and 5) were significantly correlated with the AT-WT relation trends. Component 2, which was inversely correlated with AT-WT relation trends, most strongly represented watersheds with major dams and, consequently, greater areas of open water (reservoirs), as well as dams existing in the earliest decades (1940s-1960s) as indicated by measures in the GAGES II dataset (ESM Table 3). Additionally, Component 2 had a strong negative relation with watersheds having greater woody wetland coverage. Component 3 , which was directly correlated with AT-WT relation trends, most strongly represented watersheds with greater agricultural land use and greater coverage of woody wetlands, and had negative relations with watersheds with greater deciduous forest cover (ESM Table 3). Component 5, which was inversely correlated with ATWT relation trends, represented watersheds with greater agricultural land use and greater density of major dams, and was inversely related to watershed area and the number of dams existing in the later decades (1970s-1990s) (ESM Table 3).

The majority of WT sites had increasing annual trends in both streamflow and WT (Fig. 4). Centroids of streamflow and WT trends for sites north and south of latitude $40.25^{\circ}$ indicate that streamflows increased at a greater rate in the northern part of the study area relative to those in the southern part (Fig. 4). Regression of WT trends against latitude indicated that WT trends decreased significantly $(p<0.001)$ at a rate of $0.007^{\circ} \mathrm{C}$ per degree of latitude north.

\section{Discussion}

Advantages of our dataset are that (1) all sites have a record spanning 51 years (1960-2010); (2) it covers a broad geographical area; and (3) it is data rich (51,012 AT values; 48,960 WT values). By leveraging existing information in databases, we found statistically significant increasing AT and WT trends across the mid-Atlantic region for 1960-2010. Because the data are spatially and temporally abundant, our results are statistically robust and provide trend estimates that are unlikely to be confounded by short-term climate cycles. In addition, we were able to compare trend results across the study area because all sites have a 51-year record.

The irregular-interval WT data are not ideal but also are not unique to our study (see Kaushal et al. 2010 on-line materials). We analyzed the limitations of such data by two methods and the results were consistent. The bootstrapping results indicated that the irregular-interval data did not affect the direction of the WT trends (Fig. 3). Analysis of the 


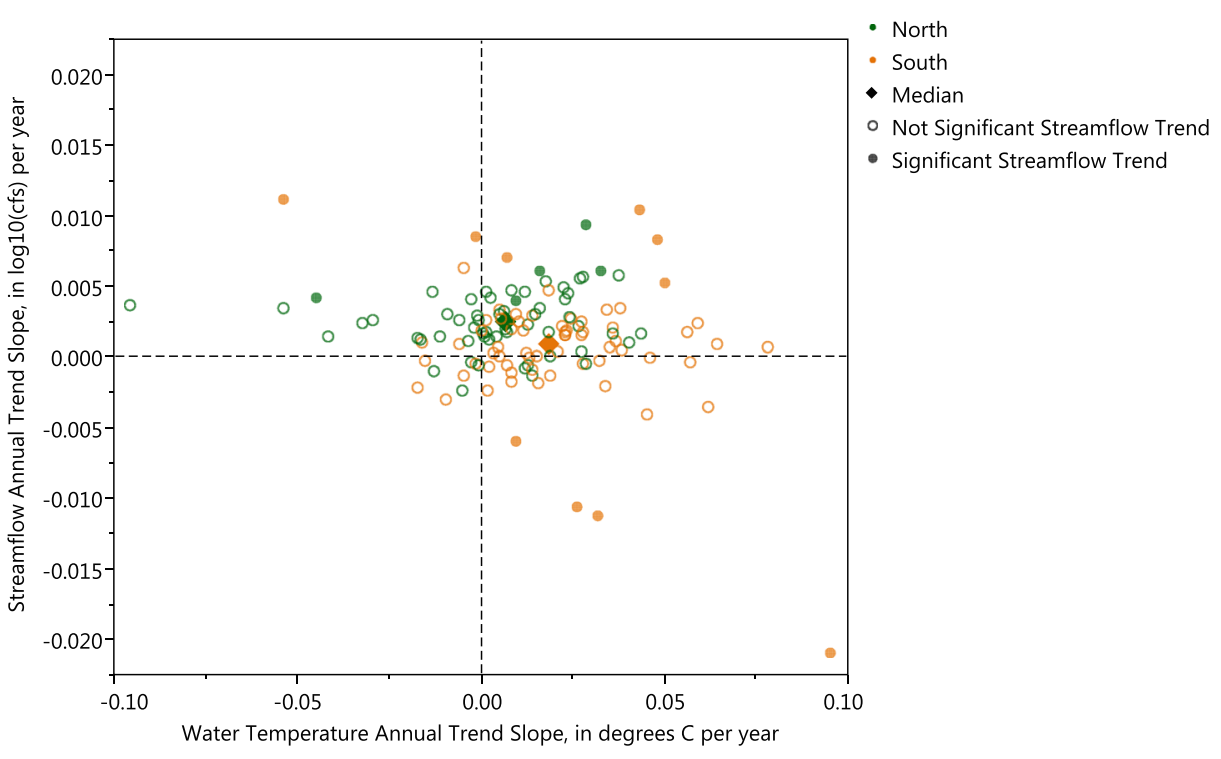

Fig. 4 Water temperature annual trend slopes vs. $\log _{10}$ streamflow annual trend slopes. Sites north and south of latitude 40.25 shown as green and orange symbols, respectively; solid and open symbols show streamflow trends that are statistically significant and not significant, respectively

51-year synthetic dataset derived from continuous WT data indicated that our trend results were conservative, i.e., for both increasing and decreasing trends, we detected fewer significant trends than were actually present (ESM Fig. 2c). Most importantly, analysis of the synthetic dataset corroborated findings of the bootstrap analysis that the irregular-interval data did not bias the results such that the direction of the detected trend was incorrect.

There was a significant shift in the mean anomaly toward warmer temperatures for the latter period (1986-2010) of 0.54 and $0.39{ }^{\circ} \mathrm{C}$ for AT and WT, respectively, relative to the former period (1961-1985). These results are notable because they indicate how quickly both AT and WT have increased in the region (Fig. 2).

Watershed characteristics, sources and volume of water, and anthropogenic influences, such as urbanization, dams, and thermal pollution, can affect WT regimes (e.g., Webb et al. 2008). Although correlation does not imply causation, we examined correlations between trends in AT-WT relations and landscape factors to evaluate whether AT-WT relation trends were synchronous with patterns in likely drivers.

Principal Components Analysis results indicated that major dams were an important factor affecting changes in the AT-WT relation in the region, specifically a decreased influence of AT on WT over time. Metrics representing major dams were inversely correlated with AT-WT relation trends, presumably because many dams release water from the hypolimnion, an effect observed by Kelleher et al. (2012) for streams in Pennsylvania, and because of a smaller surface-area:water-volume ratio $\left(\mathrm{SA}: \mathrm{W}_{\mathrm{vol}}\right)$, which reduces exposure to increasing AT. Further supporting the effect of $\mathrm{SA}: \mathrm{W}_{\mathrm{vol}}$ is that woody wetlands were directly correlated with WT increasing faster than AT over time, which we ascribe to the typically shallow, expansive waters of woody wetlands that have greater $\mathrm{SA}: \mathrm{W}_{\mathrm{vol}}$ than do dammed reservoirs.

Principal Components Analysis results also indicated that landscape factors representative of shading were drivers of AT-WT relation trends, as watersheds with greater agricultural land uses (less shading) were directly correlated with WT increasing faster than AT over time. In 
contrast, watersheds with greater deciduous forest cover were correlated with WT increasing slower than AT over time. The damping effect of major dams, however, was found to outweigh the loss of shading, as watersheds with both agriculture and major dams remained inversely correlated with positive AT-WT relation trends.

Our findings also indicated that WT increased faster than AT over time in larger watersheds, and in watersheds with greater numbers of dams present in the later decades (1970s-1990s) represented by the GAGESII dataset. The watershed-size correlation is interpreted as an exposure-time effect, similar to the exposure-volume effect of woody wetlands (or, inversely, with major dams). The correlation with more recently constructed dams also may represent the exposure time and/or volume effect. As construction of large reservoirs was less common in recent decades, these metrics may represent smaller impoundments, such as farm ponds and storm-water control basins, which likely are shallower than major impoundments and have different outlet structures (i.e., draining from the epilimnion). Such small impoundments increase exposure time to the air by increasing the time of transport to receiving waters and likely have greater $\mathrm{SA}: \mathrm{W}_{\mathrm{vol}}$ than large impoundments.

The first component of the PCA on landscape factors represented developed or urbanized land uses. This component was not significantly correlated with AT-WT relation trends, indicating that the AT-WT relation was static in the urbanized streams within our dataset. Both AT and WT, however, may have changed at rates greater than occurred in other land uses in these urbanized areas.

Increased streamflow can limit WT increases or even cause a cooling (e.g., Webb et al. 2003; Mayer 2012); therefore, we assessed the influence of streamflow on the calculated WT trends. Annual mean streamflow in the CBW increased from 1930 to 2010, with a larger increase in streams north of latitude $40.25^{\circ} \mathrm{N}$ (Rice and Hirsch 2012) as a result of increased precipitation (Karl and Knight 1998). Our $\log _{10}$ streamflow annual trend results, computed from instantaneous streamflow values, showed a larger trend in streams north of latitude $40.25^{\circ} \mathrm{N}$ (Fig. 4), consistent with results of Rice and Hirsch (2012) for annual mean streamflow. Inverse relations of WT trends with latitude indicate that rising WT was damped at greater latitude. The increase in streamflow has damped, but not stopped or reversed, the warming trend in streams in the northern part of the study area. Our finding that WT increased despite increased streamflow is consistent with analyses of the Hudson River Estuary (Seekell and Pace 2011).

For freshwaters, our results have implications for potential shifts in floral and faunal species distributions. Streams at the upper end of the WT distribution may become unsuitable habitat for certain cool-water fish species (Eaton and Scheller 1996; Isaak et al. 2012). Increasing WT also may make some streams suitable for species not currently present, allowing warm-water species, including invasive species and pathogens, to move into previously cool-water habitats. Streams draining forested watersheds with major dams warmed more slowly than other watersheds and are likely to become even more important as refugia for cool-water species in a warming world.

For Chesapeake Bay, our results have implications for potential shifts in floral and faunal species distributions and for changes in density, stratification, and eutrophication within the bay and its contributing estuaries. As eutrophic conditions have improved little over the past two decades in the Potomac River Estuary flowing into the bay (Bricker et al. 2014), our results are of particular significance with respect to nutrient fluxes to the bay. Rising WT of streams increases soluble reactive phosphorus (SRP) and to a lesser extent nitrate concentrations (Duan and Kaushal 2013). In particular, higher WT enhances reduction of iron and manganese oxides, causing release of SRP from sediments to the stream (Duan and Kaushal 2013). As WT continue to increase, the flux of SRP to the bay likely will increase, further 
thwarting land-based management measures to reduce eutrophication. Although we found a median rate of temperature increase of streams that contribute to the bay of $0.28^{\circ} \mathrm{C}$ per decade, Preston (2004) reports bay water temperature increasing at rates of 0.16 and $0.21{ }^{\circ} \mathrm{C}$ per decade at the surface and subsurface, respectively. The difference in rates suggests that bay water-residence times and mixing with ocean water help buffer the bay from the warmer water supplied from its watershed.

Despite the wide variability of the streams with respect to watershed area, channel geometry, aspect, elevation, thermal capacity, the presence or absence of riparian buffers, microclimate conditions, and land cover, on the whole, WT increased from 1960 to 2010. For sites with significantly increased WT, $85 \%$ of the variability could be explained by increased AT, despite increased streamflow at some sites. Our statistically robust results from a large dataset are consistent across the broad region, consistent with what one might expect from a physical basis, and consistent with previous analyses of AT and WT in the region.

Acknowledgments Comments of three anonymous journal reviewers significantly strengthened the analysis. We also appreciate discussions with and/or reviews by Linda K. Blum, Jeffrey G. Chanat, George M. Hornberger, Aaron L. Mills, Michael L. Pace, and David A. Seekell.

\section{References}

Arismendi I, Johnson SL, Dunham JB, Haggerty R, Hockman-Wert D (2012) The paradox of cooling streams in a warming world: regional climate trends do not parallel variable local trends in stream temperature in the pacific continental United States. Geophys Res Lett 39:L10401. doi:10.1029/2012GL051448

Beitinger TL, Bennett WA, McCauley RW (2000) Temperature tolerances of North American freshwater fishes exposed to dynamic changes in temperature. Environ Biol Fish 58:237-275. doi:10.1023/A:1007676325825

Bricker SB, Longstaff B, Dennison W, Jones A, Boicourt K, Wicks C, Woerner J (2007) Effects of nutrient enrichment in the Nation's estuaries: a decade of change, National Estuarine Eutrophication Assessment Update. NOAA Coastal Ocean Program Decision Analysis Series No. 26. National Centers for Coastal Ocean Science, Silver Spring, MD. 322 p

Bricker SB, Rice KC, Bricker OP (2014) From headwaters to coast: influence of human activities on water quality of the Potomac River Estuary. Aquat Geochem 20:291-323. doi:10.1007/s10498-014-9226-y

Caissie D (2006) The thermal regime of rivers: a review. Freshw Biol 51:1389-1406

Cochrane D, Orcutt GH (1949) Application of least squares regression to relationships containing auto-correlated error terms. J Am Stat Assoc 44:32-61. doi:10.1080/01621459.1949.10483290

Coles JF, Jones RC (2000) Effect of temperature on photosynthesis-light response and growth of four phytoplankton species isolated from a tidal freshwater river. J Phycol 36:7-16. doi:10.1046/j.1529-8817.2000. 98219.x

Donat MG, Alexander LV (2012) The shifting probability distribution of global daytime and night-time temperatures. Geophys Res Lett 39: doi:10.1029/2012GL052459

Duan S-W, Kaushal SS (2013) Warming increases carbon and nutrient fluxes from sediments in streams across land use. Biogeosciences 10:1193-1207. doi:10.5194/bg-10-1193-2013

Eaton JG, Scheller RM (1996) Effects of climate warming on fish thermal habitat in streams of the United States. Limnol Oceanogr 41(5):1109-1115

Efron B (1979) Bootstrap methods: another look at the jackknife. Ann Stat 7:1-26

Falcone JA, Carlisle DM, Wolock DM, Meador MR (2010) GAGES: a stream gage database for evaluating natural and altered flow conditions in the conterminous United States. Ecology 91:621-621. doi:10.1890/090889.1

Hagy JD, Boynton WR, Keefe CW, Wood KV (2004) Hypoxia in Chesapeake Bay, 1950-2001: long-term change in relation to nutrient loading and river flow. Estuaries 27(4):634-658

Harley CDG, Randall Hughes A, Hultgren KM, Miner BG, Sorte CJB, Thornber CS, Rodriguez LF, Tomanek L, Williams SL (2006) The impacts of climate change in coastal marine systems. Ecol Lett 9:228-241. doi:10. 1111/j.1461-0248.2005.00871.x 
Helsel DR, Hirsch RM (1992) Statistical methods in water resources. Elsevier, Amsterdam

IPCC (2013) Climate change 2013: the physical science basis, summary for policymakers. Working Group 1 Contribution to the Fifth Assessment Report (http://www.climatechange2013.org/images/uploads/WGIAR5SPM_Approved27Sep2013.pdf)

Isaak DL, Wollrab S, Horan D, Chandler G (2012) Climate change effects on stream and river temperatures across the northwest U.S. from 1980-2009 and implications for salmonid fishes. Clim Chang 113:499-524

Johnson SL (2003) Stream temperature: scaling of observations and issues for modeling. Hydrol Proc 17:497499. doi:10.1002/hyp.5091

Karl TR, Knight RW (1998) Secular trends of precipitation amount, frequency, and intensity in the United States. Bull Am Meteorol Soc 79(2):231-241

Kaushal SS, Likens GE, Jaworski NA, Pace ML, Sides AM, Seekell D, Belt KT, Secor DH, Wingate RL (2010) Rising stream and river temperatures in the United States. Frontiers Ecol Environ 8(9):461-466. doi:10. 1890/090037

Kelleher C, Wagner T, Gooseff M, McGlynn B, McGuire K, Marshall L (2012) Investigating controls on the thermal sensitivity of Pennsylvania streams. Hydrol Proc 26:771-785

Mayer TD (2012) Controls of summer stream temperature in the Pacific Northwest. J Hydrol 475:323-335. doi: 10.1016/j.jhydrol.2012.10.012

Moatar F, Gailhard J (2006) Water temperature behaviour in the River Loire since 1976 and 1881. Compt Rendus Geosci 338:319-328

Mohseni O, Erickson TR, Stefan HG (1999) Sensitivity of stream temperatures in the United States to air temperatures projected under a global warming scenario. Water Resour Res 35(12):3723-3733

Najjar RG, Pyke CR, Adams MB, Breitburg D, Hershner C, Kemp M, Howarth R, Mulholland MR, Paolisso M, Secor D, Sellner K, Wardrop D, Wood R (2010) Potential climate-change impacts on the Chesapeake Bay. Estuar Coast Shelf Sci 86:1-20

Preston BL (2004) Observed winter warming of the Chesapeake Bay Estuary (1949-2002): implications for ecosystem management. Environ Manag 34(1):125-139. doi:10.1007/s00267-004-0159-x

Rabalais NN, Turner RE, Diaz RJ, Justic D (2009) Global change and eutrophication of coastal waters. ICES J Mar Sci 66:1528-1537

Rice KC, Hirsch RM (2012) Spatial and temporal trends in runoff at long-term streamgages within and near the Chesapeake Bay watershed. USGS SIR 2012-5151:56

Scavia D, Field JC, Boesch DF, Buddemeier RW, Burkett V, Cayan DR, Fogarty M, Harwell MA, Howarth RW, Mason C, Reed DJ, Royer TC, Sallenger AH, Titus JG (2002) Climate change impacts on U.S. coastal and marine ecosystems. Estuaries 25:149-164

Schertz TL, Alexander RB, Ohe DJ (1991) The computer program estimate trend (ESTREND), a system for the detection of trends in water-quality data: water-resources investigations report. US Geological Survey, Reston Virginia

Seekell DA, Pace ML (2011) Climate change drives warming in the Hudson River Estuary, New York (USA). J Environ Monit 13:2321-2327

Shaw PJA (2003) Multivariate statistics for the environmental sciences. Oxford University Press, New York

Short FT, Neckles HA (1999) The effect of global climate change on seagrasses. Aquat Bot 63(3-4):169-196

van Vliet MTH, Ludwig F, Zwolsman JJG, Weedon GP, Kabat P (2011) Global river temperatures and sensitivity to atmospheric warming and changes in river flow. Water Resour Res 47:W01544. doi:10.1029/ 2010WR009198

van Vliet MTH, Ludwig F, Kabat P (2013) Global streamflow and thermal habitats of freshwater fishes under climate change. Clim Chang. doi:10.1007/s10584-013-0976-0

Webb BW, Nobilis F (2007) Long-term changes in river temperature and the influence of climatic and hydrological factors. Hydrol Sci J 52(1):74-85

Webb BW, Clack PD, Walling DE (2003) Water-air temperature relationships in a Devon river system and the role of flow. Hydrol Proc 17:3069-3084

Webb BW, Hannah DM, Moore RD, Brown LE, Nobilis F (2008) Recent advances in stream and river temperature research. Hydrol Proc 22:902-918 